\title{
Physical Activity Performance among Obese Adolescents Who Are Enrolled in the Obesity Treatment Program: A Comparative Study
}

\author{
Malak Al Qahtani', Einas Al Eisa² \\ ${ }^{1}$ Public Health, Directorate of Health Affairs in Riyadh, Riyadh, Saudi Arabia \\ ${ }^{2}$ Rehabilitation Sciences Department, College of Applied Medical Sciences, King Saud University, \\ Riyadh, Saudi Arabia \\ Email: malakqahtani1@gmail.com
}

Received 15 June 2016; accepted 2 August 2016; published 5 August 2016

Copyright (C) 2016 by authors and Scientific Research Publishing Inc.

This work is licensed under the Creative Commons Attribution International License (CC BY).

http://creativecommons.org/licenses/by/4.0/

(c) (i) Open Access

\section{Abstract}

Existing literature indicates that a weight-management program that includes diet modification, Physical Activity (PA) instructions and behavioral modification in weight reduction increases obese adolescents' participation in PA. However, the effect of such a program on obese Saudi adolescents is unknown. Objective: To examine the effects of a weight-management program in terms of decreasing Body Mass Index (BMI) and improving participation in PA in obese Saudi adolescents, and to establish whether differences exist between genders in response to a weight-management program. PA was measured by Arab Teens Life Style (ATLS) questionnaire for both groups. Results: $A$ wide range of differences in $P A$ and sedentary time are evident between new and weightmanaged patients and two genders. PA performance was significantly higher among the weightmanaged patients compared with new patients. Also, for boys there were no differences between both groups in PA performance. While, girls' PA was significantly higher among the girls in weightmanaged group compared with girls in new patients group. Weight-managed patients spend significantly less time on the computer and/or the Internet per day compared with new patients. After treatment, the mean BMI among the weight-managed patients slightly decreased. Conclusion: The study findings suggest that the weight-management program could be effective in treating Saudi obese adolescents due to its effect in BMI reduction and greater improvement in PA performance. The surprising result from this study, PA differences between the groups were because of the total PA of girls only, meaning that obesity treatment program can lower the percentage of obesity among women and increase their levels of physical activity.

\section{Keywords}

Obesity, Adolescents, Physical Activity, BMI, Weight-Management Program, Sedentary Behaviors

How to cite this paper: Al Qahtani, M. and Al Eisa, E. (2016) Physical Activity Performance among Obese Adolescents Who Are Enrolled in the Obesity Treatment Program: A Comparative Study. Open Journal of Therapy and Rehabilitation, 4, 163173. http://dx.doi.org/10.4236/ojtr.2016.43015 


\section{Introduction}

Obesity in adolescents and children has risen to significant levels globally with serious public health consequences [1]. Adolescence is a critical period in human life because it is marked by decrease in physical activity levels and accumulation of fat cells especially in girls [2]. In a recent study, estimates of overweight and obesity prevalence among Saudi adolescents aged 13 - 18 years were $36.6 \%$ for males and $38.4 \%$ for females [3]. Also, the high prevalence of physical inactivity, sedentary behaviors and unhealthy diet among Saudi adolescents is a major health problem [4]. Physical inactivity and obesity are risk factors for many chronic diseases, including cardiovascular disease, diabetes mellitus, osteoporosis, osteoarthritis, and depression [5]. Participation in PA is a main component of energy expenditure in adolescents and leads to many health benefits such as improved cardiovascular and metabolic fitness as well as bone health [6]. Recent guidelines on recommended levels of PA for children and adolescents ( 5 - 18 years) indicate that they should engage in moderate to vigorous-intensity PA for at least one hour/daily and they should minimize the amount of time being sedentary [7]. Sedentary behavior where sitting or lying is the dominant mode of individual leads to lower energy expenditure [8]. In addition, recent research findings have shown that no relation between TV viewing hours and PA participation is independently associated with metabolic risk [9]. Weight management program based on behavioral modification that includes 3 primary components: diet, exercise, and behavior therapy has positive clinical outcomes in adults [10], but in adolescents only few studies have reported successful weight management intervention [11]. Recent Cochrane review conducted by Luttikhuiss and colleagues (2009) found limited numbers of adolescent obesity treatment studies, none of which were from the Arab world. However, studies evaluating the effect of adolescent weigh management program on their PA are limited in both quantity and quality [12]. Measuring PA following obesity program is important for understanding how intervention affects behavior that influences energy expenditure in obese adolescents. Furthermore, studies about PA levels among Saudis remain inadequate. To our knowledge, there are no studies measuring PA levels among obese adolescents after an intervention. The major aims of this study were: 1) to measure the effectiveness of the obesity treatment program provided by the obesity clinic based on differences in PA performance and sedentary behaviors between the two groups and measuring the differences in BMI of the weight-managed obese group at their first visit to the clinic and after three months of treatment. 2) Does gender affect adolescents' responses to an obesity treatment program? This study aims to verify the following hypotheses: The obesity treatment program will positively influence participation in PA and effectively reduce BMI. Also, boys in weight-managed group will participate in PA more than boys in new patients group while girls had similar level of PA in the two groups.

\section{Materials and Methods}

Data were collected in period from February until the end of May 2014.

\subsection{Participants}

One hundred obese adolescents were recruited in this study. Fifty weight-managed obese and fifty control obese adolescents from the first visit from the obesity clinic at King Khaled University Hospital at Riyadh (KKUH). A comparative cross-sectional study design was used for this study. For both groups, a convenient coverage sampling has been used. Obesity clinic in KKUH is a multidisciplinary clinic, where the patient can see all the subspecialties in a single visit. The weight-management program includes diet, promotion of PA, reduction in sedentary behavior particularly screen-media use. Program components: at the first visit patients see all specialist and the anthropometric measures taken. Then, the patients enrolled in the weight-management program for three months. Physical therapist explains all aspects of exercise and design a program for each patient after evaluation of their current level of PA. Aerobic exercises included three times a week for a minimum of 20 minutes per session like walking, jogging, cycling, swimming, and dancing. Recommend each patient to accumulate 60 minutes of moderate exercise daily. Behavioral modifications included such as using stairs instead of an elevator, and decrease the sitting time. Also, decrease the time spent in sedentary activities such as television viewing, use of the computer, and video game playing to 2 hours/daily according to American academy of pediatrics [13]. Also, dietitian recommended according to American heart association use of a reduced-energy diet (not less than $1200 \mathrm{kcal}[5040 \mathrm{~kJ}] /$ day) and focus on fruit and vegetables [14]. 
Inclusion criteria:

Age between 12 - 18 years male and female. BMI > 95th. BMI was classified according to the International Obesity Task Force (IOTF) criteria age and sex-specific BMI cut-offs from international guidelines [15]. Weightmanaged obese adolescents enrolled in the weight-management program for three months (weight management group). Obese adolescents on their first visit to the same clinic (new patients group).

Exclusion criteria:

The exclusion criteria include patients who had bariatric surgery, mental retardation, participation in other obesity treatment programs, disorders interfering with growth and development or weight or medical conditions causing inability to participate in PA.

\subsection{Instrumentation}

\subsubsection{Anthropometric Measurement}

Body weight and height were obtained for all participants at baseline measurement from the patients' medical records at the first visit and after a three-month weight-management program for the intervention group. For the new patients group, body weight and height were obtained from medical records for new patients on their first visit to the clinic. Digital weight and mechanical height scale (DetectoProDocSerries physician Digital Scale) was used in anthropometric measurement room by nurses while participants were barefooted and without excess outer clothing. BMI was calculated as weight $\mathrm{kg} /$ height $\mathrm{m}^{2}$.

\subsubsection{PA Performance Measurement}

A self-report questionnaire was used to assess the PA and sedentary activity of the both groups. This research tool was used in the Arab Teens Lifestyle Study (ATLS) [16] and contained 47 items relating to of PA, sedentary behaviors (television viewing time and computer use). The physical activity questionnaire was previously shown to have a high reliability (ICC $=0.85 ; 95 \% \mathrm{CL}=0.70-0.93)$ and an acceptable validity $(r=0.30 ; p<$ 0.05 ) against pedometer on a sample of males 15 - 25 years old [16]. Also, it was found to have a validity coefficient of $0.37(p<0.05)$ in a study involving both males and females aged 14 - 19 years against pedometer [17]. The physical activity questionnaire covers all domains of physical activity including transport, household, fitness, and sports activities. Moderate Physical Activity (MPA) includes activities such as normal walking, brisk walking, recreational swimming, household activities, volleyball and table tennis. Vigorous Physical Activity (VPA) included activities such as stair climbing, jogging, running, cycling, self-defense, weight training, soccer, basketball, handball, and singles tennis. Physical activities were assigned metabolic equivalent (MET) values based on the compendium of physical activity [18] and the compendium of physical activity for youth [19]. Moderate-intensity recreational sports were assigned an average MET value equivalent to 4 METs. Vigorousintensity sports were assigned an average MET value equivalent to 8 METs. Slow walking, normal pace walking, and brisk walking were assigned MET values of 2.8, 3.5, and 4.5 METs, respectively. The questionnaire allows the calculation of total energy expenditure per week based on MET values of all types of physical activities reported by the participant. To measure the participants' levels of physical activity, the total METs min per week and the METs min per week spent in vigorous physical activity were used. The classifications for activity levels were based on 2 cut-off points of 30 minutes and 60 minutes per day of moderate level of physical activity. This was then converted into 3 activity categories based on total METs minute per week as follows: active $>1680$ METs per week ( 60 minutes $\times 7$ days 4 METs). Minimally active: $>840<1680$ METs per week (30 minutes $\times 7$ days $\times 4$ METs). In active: $<840$ METs min per week [20].

\subsection{Statistical Analysis}

Data were presented using mean and Standard Deviation (SD) for continuous data and frequencies, and percentages for categorical data. Continuous variables (such as BMI or MET minutes per week) between groups (new patients and weight-managed patients) were tested using student t-test. Categorical variables (such as gender or watching TV) between groups were tested using chi-square test. The change of BMI between baseline and after treatment was examined using the Wilcoxon signed-rank test. All $p$-values were two-tailed. Alpha level was set at $p$-value $<0.05$ was considered significant. SPSS software (release 22, SPSS Inc., Chicago, U.S.) was used for all statistical analyses. 


\section{Results}

The descriptive characteristics of the main dependent variables of the 100 participants are presented in Table 1.

\subsection{Differences in PA Performance between the Two Groups}

Total PA were significantly higher among the weight-managed patients compared with new patients (859.9 \pm 972.5 METs min versus 507.9 \pm 769.8 METs min, $p=0.048$ ). The MET minutes per week of all types of vigorous physical activity was slightly higher among the weight-managed patients compared with new patients, however the difference was not significant (422.0 \pm 655.7 versus $372.2 \pm 662.2, p=0.706)$. The MET minutes per week of all types of moderate physical activity was significantly higher among the weight-managed patients compared with new patients (437.9 \pm 689.3 versus $135.7 \pm 235.4, p=0.004)$. Similar results were shown with walking and moderate-intensity sports ( $p=0.001$ and 0.026 , respectively) as shown in Table 2 . Table 3 shows the means (and standard deviations) of the time spent in physical activity (in minutes per week) by the study groups. The time spent in minutes per week on all types of vigorous physical activity was slightly higher among the weight-managed patients compared with new patients, however the difference was not significant (53.2 \pm 82.3 versus $46.5 \pm 82.8, p=0.686$ ). The time spent in minutes per week on all types of moderate physical activity was significantly higher among the weight-managed patients compared with new patients (142.0 \pm 153.2 versus $81.2 \pm 96.2, p=0.019$ ). The overall time spent in minutes per week on both moderate and vigorous physical activity was significantly higher among the weight-managed patients compared with new patients (195.2 \pm 192.8 versus $127.7 \pm 130.7, p=0.043)$. Figure 1 shows the of physical activity levels based on MET minutes per week by study groups. Weight-managed patients were slightly less inactive than new patients (62.0\% versus $80.0 \%)$, but the difference did not reach statistical significance $(p=0.154)$. Similarly, weight-managed patients were slightly more active than new patients (16.0\% versus $10.0 \%)$, but the difference did not reach statistical significance $(p=0.154)$.

\subsection{PA Differences between Groups by Gender}

For boys, there were no differences between the two study groups in the MET minutes per week for any VPA, MPA, and total PA using two-sample t-test ( $p=0.814, p=0.192, p=0.562$, respectively). For girls, the MET minutes per week for any MPA and total PA (but not VPA alone) were significantly higher among the weight-managed patients compared with new patients ( $p=0.003, p=0.005, p=0.136$, respectively), as illustrated in Table 4.

Table 1. The descriptive characteristics of the main dependent variables of the participants.

\begin{tabular}{|c|c|c|c|c|}
\hline & \multicolumn{3}{|c|}{ Participants } & \multirow[b]{2}{*}{$p$-value } \\
\hline & New patients & Weight-managed patients & Total & \\
\hline Age (years) & $15.2 \pm 2.5$ & $15.2 \pm 2.3$ & $15.2 \pm 2.4$ & 0.901 \\
\hline Weight (Kg) & $112.2 \pm 31.6$ & $101.2 \pm 24.0$ & $106.7 \pm 28.4$ & 0.052 \\
\hline Height (cm) & $161.9 \pm 9.5$ & $161.4 \pm 8.2$ & $161.7 \pm 8.8$ & 0.781 \\
\hline BMI-baseline & $42.2 \pm 8.8$ & $38.5 \pm 7.5$ & $40.3 \pm 8.3$ & 0.029 \\
\hline \multicolumn{5}{|l|}{ Gender } \\
\hline Boys & $24(48.0 \%)$ & $23(46.0 \%)$ & $47(47.0 \%)$ & 0.841 \\
\hline Girls & $26(52.0 \%)$ & $27(54.0 \%)$ & $53(53.0 \%)$ & \\
\hline \multicolumn{5}{|l|}{ School } \\
\hline Middle school & $29(58.0 \%)$ & $28(56.0 \%)$ & $57(57.0 \%)$ & 0.840 \\
\hline Secondary school & $21(42.0 \%)$ & $22(44.0 \%)$ & $43(43.0 \%)$ & \\
\hline
\end{tabular}

${ }^{*} p$-value of t-test ample. 
Table 2. Mean and standard deviation of MET minutes per week by the study groups 1.

\begin{tabular}{|c|c|c|c|c|}
\hline & New patients & Weight-managed patients & Total & $p$-value ${ }^{*}$ \\
\hline Vigorous physical activity & $372.2 \pm 662.2$ & $422.0 \pm 655.7$ & $397.1 \pm 656.1$ & 0.706 \\
\hline Stair climbing & $45.8 \pm 18.2$ & $51.4 \pm 17.6$ & $48.6 \pm 18.0$ & 0.119 \\
\hline Running & $14.4 \pm 59.8$ & $28.8 \pm 122.6$ & $21.6 \pm 96.2$ & 0.457 \\
\hline Biking & $68.0 \pm 249.6$ & $110.4 \pm 421.3$ & $89.2 \pm 345.2$ & 0.542 \\
\hline Vigorous-intensity sports & $244.0 \pm 551.3$ & $204.0 \pm 422.2$ & $224.0 \pm 488.9$ & 0.685 \\
\hline Self-defense & $0.0 \pm 0.0$ & $16.0 \pm 113.1$ & $8.0 \pm 80.0$ & 0.320 \\
\hline Weight training & $0.0 \pm 0.0$ & $11.4 \pm 65.5$ & $5.7 \pm 46.5$ & 0.222 \\
\hline Moderate physical activity & $135.7 \pm 235.4$ & $437.9 \pm 689.3$ & $286.8 \pm 534.4$ & $0.004^{*}$ \\
\hline Walking & $41.3 \pm 114.4$ & $212.1 \pm 334.9$ & $126.7 \pm 263.4$ & $0.001^{*}$ \\
\hline Swimming & $28.8 \pm 122.6$ & $102.6 \pm 436.4$ & $65.7 \pm 321.0$ & 0.252 \\
\hline Moderate-intensity sports & $16.0 \pm 47.1$ & $0.8 \pm 5.7$ & $8.4 \pm 34.3$ & $0.026^{*}$ \\
\hline Household activities & $31.6 \pm 112.7$ & $68.4 \pm 137.6$ & $50.0 \pm 126.5$ & 0.147 \\
\hline Dancing & $18.0 \pm 72.0$ & $54.0 \pm 268.9$ & $36.0 \pm 196.7$ & 0.363 \\
\hline Total physical activity & $507.9 \pm 769.8$ & $859.9 \pm 972.5$ & $683.9 \pm 890.3$ & $0.048^{*}$ \\
\hline
\end{tabular}

" $p$-value of two-sample t-test.

Table 3. Mean (and standard deviation) of time spent in physical activity (in minutes per week) by the study groups. Mean and standard deviation of MET minutes per week by the study groups 1 .

\begin{tabular}{ccccc}
\hline & New patients & Weight-managed patients & Total & $p$-value \\
\hline Vigorous physical activity & $\mathbf{4 6 . 5} \pm \mathbf{8 2 . 8}$ & $\mathbf{5 3 . 2} \pm \mathbf{8 2 . 3}$ & $\mathbf{4 9 . 9} \pm \mathbf{8 2 . 2}$ & 0.686 \\
Stair climbing & $5.7 \pm 2.3$ & $6.4 \pm 2.2$ & $6.1 \pm 2.2$ & 0.120 \\
Running & $1.8 \pm 7.5$ & $3.6 \pm 15.3$ & $2.7 \pm 12.1$ & 0.471 \\
Biking & $8.5 \pm 31.2$ & $13.8 \pm 52.7$ & $11.1 \pm 43.1$ & 0.542 \\
Vigorous-intensity sports & $31.1 \pm 69.5$ & $25.5 \pm 52.8$ & $28.3 \pm 61.4$ & 0.651 \\
Self-defense & $0.0 \pm 0.0$ & $2.0 \pm 14.1$ & $1.0 \pm 10.0$ & 0.320 \\
Weight training & $0.0 \pm 0.0$ & $1.9 \pm 10.9$ & $1.0 \pm 7.8$ & 0.231 \\
Moderate physical activity & $\mathbf{8 1 . 2} \pm \mathbf{9 6 . 2}$ & $\mathbf{1 4 2 . 0} \pm \mathbf{1 5 3 . 2}$ & $\mathbf{1 1 1 . 6} \pm \mathbf{1 3 0 . 9}$ & $0.019^{*}$ \\
Walking & $60.9 \pm 89.9$ & $96.8 \pm 105.7$ & $78.9 \pm 99.3$ & 0.070 \\
Swimming & $4.8 \pm 20.4$ & $17.1 \pm 72.7$ & $11.0 \pm 53.5$ & 0.252 \\
Moderate-intensity sports & $4.3 \pm 12.1$ & $0.2 \pm 1.4$ & $2.2 \pm 8.7$ & $0.021^{*}$
\end{tabular}

${ }^{*} p$-value of two-sample t-test. 


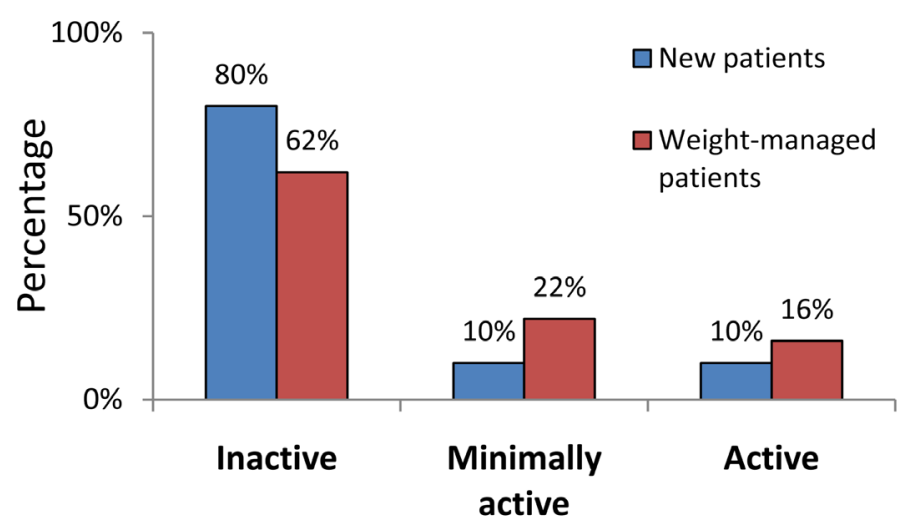

Figure 1. Physical activity levels based on MET minutes per week by study groups. ${ }^{*}$-value of chi-square.

Table 4. Mean (and standard deviation) of MET minutes per week by the study groups and gender.

\begin{tabular}{|c|c|c|c|c|}
\hline & New patients & Weight-managed patients & Total & $p$-value \\
\hline \multicolumn{5}{|l|}{ Boys $(\mathrm{N}=47)$} \\
\hline Vigorous physical activity & $616.9 \pm 843.5$ & $559.2 \pm 831.2$ & $588.7 \pm 828.9$ & 0.814 \\
\hline Moderate physical activity & $167.2 \pm 299.4$ & $404.6 \pm 823.5$ & $283.4 \pm 619.3$ & 0.192 \\
\hline Total physical activity & $784.1 \pm 984.8$ & $963.7 \pm 1122.2$ & $872.0 \pm 1046.6$ & 0.562 \\
\hline \multicolumn{5}{|l|}{ Girls $(N=53)$} \\
\hline Vigorous physical activity & $146.3 \pm 307.0$ & $305.2 \pm 441.3$ & $227.2 \pm 386.1$ & 0.136 \\
\hline Moderate physical activity & $106.6 \pm 156.1$ & $466.3 \pm 565.5$ & $289.9 \pm 452.2$ & $0.003^{*}$ \\
\hline Total physical activity & $252.9 \pm 358.5$ & $771.5 \pm 836.1$ & $517.1 \pm 692.7$ & $0.005^{*}$ \\
\hline \multicolumn{5}{|l|}{ Total $(\mathrm{N}=100)$} \\
\hline Vigorous physical activity & $372.2 \pm 662.2$ & $422.0 \pm 655.7$ & $397.1 \pm 656.1$ & 0.706 \\
\hline Moderate physical activity & $135.7 \pm 235.4$ & $437.9 \pm 689.3$ & $286.8 \pm 534.4$ & $0.004^{*}$ \\
\hline Total physical activity & $507.9 \pm 769.8$ & $859.9 \pm 972.5$ & $683.9 \pm 890.3$ & $0.048^{*}$ \\
\hline Dancing & $4.5 \pm 16.0$ & $12.3 \pm 57.3$ & $8.6 \pm 42.8$ & .409 \\
\hline Total physical activity & $127.7 \pm 130.7$ & $195.2 \pm 192.8$ & $161.5 \pm 167.3$ & $.043^{*}$ \\
\hline
\end{tabular}

${ }^{*} p$-value of two-sample t-test.

\subsection{Differences in Sedentary Behavior-(TV Viewing + Computer Usage)}

Approximately $45 \%$ of the patients watch TV and/or DVD/Video for two hours or more per day, with no difference between the groups $(p=0.841)$. Approximately $50 \%$ of the patients spend 5 hours of more time on the computer and/or the internet per day, with weight-managed patients spend significantly less time on the computer and/or the internet per day as compared with new patients $(p=0.046)$ as illustrated in Table 5.

\subsection{BMI before and after Treatment}

Figure 2 shows the mean BMI before and after treatment among the weight-managed patients $(\mathrm{N}=50)$. After treatment, the mean BMI slightly decreased from (from 38.91 to 38.34). The difference was significant using the Wilcoxon signed ranks test (value $-2.196, p=0.028$ ) but did not reach statistical significance using the paired t-test (value 0.746, $p=0.459$ ). 


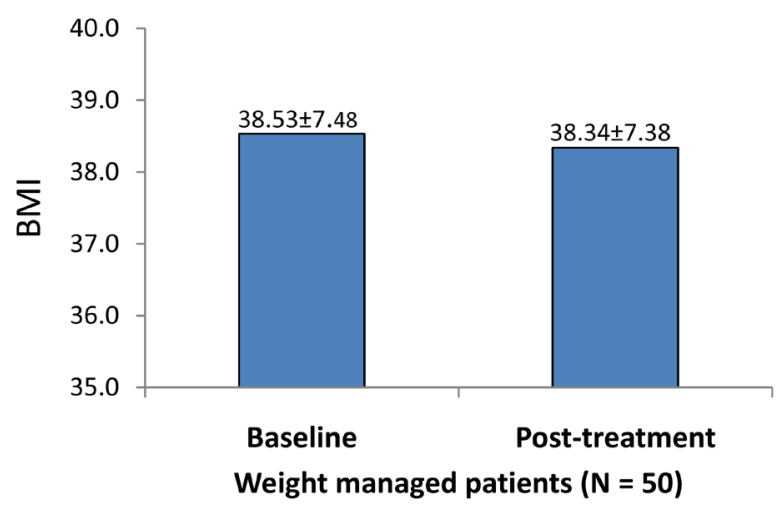

Figure 2. Physical activity levels based on MET min per week by the study group. ${ }^{*} p$-value of paired t-test.

Table 5. Time spent in TV and computer of the study groups.

\begin{tabular}{ccccc}
\hline & New patients & Weight-managed patients & Total & $p$-value \\
\hline Time spent on computer (hrs/day) & 4 hours or less $20(40.0 \%)$ & $30(60.0 \%)$ & $50(50.0 \%)$ & $0.046^{*}$ \\
& 5 hours or more $30(60.0 \%)$ & $20(40.0 \%)$ & $50(50.0 \%)$ & 0.841 \\
\hline Time spent on TV (hrs/day) & One hour or less 27 (54.0\%) & $28(56.0 \%)$ & $55(55.0 \%)$ \\
\hline
\end{tabular}

${ }^{*} p$-value of chi-square.

\section{Discussion}

A The purpose of the study was to compare PA performance between obese adolescents visiting the obesity clinic for the first time and weight-managed obese adolescents enrolled in an obesity treatment program for three months. In addition, the study aimed to measure the effectiveness of the obesity treatment program provided by the obesity clinic at KKUH based on differences in PA performance between the two groups and measuring the differences in BMI of the weight-managed obese group at their first visit to the clinic and after three months of treatment.

\subsection{PA Performance Differences between Groups}

Our study found that PA participation was significantly higher among the weight-managed patients compared with new patients. The foundation of successful weight loss involves caloric deficits, where the metabolic cost of exercise exceeds energy intakes, leading to reductions in body weight [21]. Many studies indicate that evidence-based multidisciplinary treatment that include diet, exercise and behavioral modification can increase daily PA among overweight and obese adolescents [22]-[25]. A review by Seo and Sa [26] looked at indirect comparisons of different weight management interventions (e.g., physical activity alone; diet and behavioral modification; and diet, physical activity, and behavioral modification). Diet, physical activity, and behavioral modification had the greatest mean effect size. In contrast, a review provides evidence that physical activity interventions have had only a small effect (approximately 4 minutes more walking or running per day) on children's PA level [27]. The differences in physical activity measures between the weight managed group and new patients group were found in the MPA and total PA but not VPA. In terms of VPA, all participants of our study spent significantly less time per week engaged in vigorous activities. That may describe the small change of BMI between the first visit and after 3 months of treatment of weight-managed group. Numerous studies have shown a direct relationship between higher PA levels and lower prevalence rates of obesity-related health risks [5], [28]. Although, current clinical guidelines specific to weight loss primarily focus on low to moderate intensity PA, however, this may not provide adequate time to allow the body to physiologically maintain for adequate duration to maintain this aerobic process to receive weight loss benefit [29] [30]. Overall, the participants' PA percentage increased after participating in the program. For the weight-managed group, the inactivity percentage was $62 \%$ while $80 \%$ of the new patient group were inactive. $22 \%$ of weight-managed group are minimally ac- 
tive while only $10.0 \%$ of the new patient group are minimally active. $16.0 \%$ of weight-managed group are active and only $10 \%$ of the new patient group are active. A Quarter third of overall participants are inactive, which is consistent with the results of national study that used objective monitoring of daily PA levels of Saudi adolescents [31].

\subsection{PA Differences between Groups by Gender}

The results provide support for all hypotheses except the hypothesis, which stated that boys would participate in PA more than girls after treatment. The current study found higher PA level in girls in weight-managed compared with girls in new patients group while; boys had almost similar level of PA in the two groups. These findings might be a sign that a weight-management program provided by the specialists in the clinic was effective in increasing participation of obese girls in PA; however, it is still too early to draw any firm conclusions of this nature until more results are proved by an objective scale. The literature suggests that the obesity treatment programs must be design with specific gender-based consideration [32] [33]. In a recent study conducted by Al Eisa et al. (2014) [34] found that the mean numbers of steps of Saudi female students increased in three weeks after an intervention based on PA recommendation. Also, a research indicates that female adolescents benefit from consultation with health providers regarding healthy life style to achieve or maintain a healthy body weight [35]. Possible reasons for differences in PA performance between boys and girls could be the self-reporting questionnaire that led to over-reporting of the levels of PA in order to meet the social expectations of movement. Furthermore, a person's perception of the amount of effort required to perform an activity is also involved in their assessment of whether an activity should be characterized as being at a low, moderate or high level [36]. This means that weight management program programs should be customized to each individual, with gender as a primary consideration [37]. Hence, further studies are needed to understand the barriers preventing obese boys from engaging in more activities after a weight-management program.

\subsection{Time Spent in TV and Computer of the Study Groups}

The relationship between PA and sedentary behaviors plays a fundamental role in energy expenditure [38]. Approximately $45 \%$ of the patients in our study watch TV and/or DVDs/Videos for two hours or more per day, with no difference between the groups, while $50 \%$ of the patients spend five or more hours on the computer and/or the internet per day, with weight-managed patients spending significantly less time on the computer and/or the internet per day compared with new patients. A very high percentage (84\% for males and $91.2 \%$ for females) of Saudi adolescents spent more than 2 hours on TV viewing and computer use [4]. There were significant associations between BMI, PA and sedentary behaviors; the youth with higher BMI reported lower levels of PA and higher amounts of sedentary time [39]. According to a study on adolescents there is a strong positive relationship between TV viewing hours and BMI [40]. Also, playing electronic games for more than one hour per day was significantly related to obesity in adolescents [41]. Consequently, increasing screen time will decrease the time of activity and increase unhealthy eating which lead to obesity among adolescents [42].

\subsection{BMI before and after Treatment}

In this study, the mean BMI slightly decreased from 38.91 to 38.34 after treatment. The change in body weight status that might be desirable in an adolescent obesity treatment intervention is uncertain [43]. Some previous studies found a significant effect of 6 months of weight-management programs on lowering BMI [44]. Also, interventions of 10 to 12 weeks of weight-management program have significant reduction of BMI of obese adolescents [45]. In contrast, after 12 months of standard obesity rehabilitation plus planned individual PA, an improvement was observed in the PA of obese patients but no reduction of body weight compared with standard care [46]. In a Malaysian study there was no BMI reduction but no weight gain after obesity treatment program [47].

\section{Strength and Limitation of the Study}

The KSA has witnessed significant lifestyle changes during the last three decades. Subsequently, physical inactivity, sedentary lifestyle and an ever-increasing rate of obesity have become prevalent in Saudi society (Al Hazzaa, 2007). This study has a number of strengths including the use of appropriate tools for data collection; 
the PA questionnaire was validated on Saudi youths. Furthermore, there were no differences in the baseline characteristics between the participants in the intervention group and the control group. Also, the present study is the first of its kind to be conducted that provides comparative data on the PA performance of adolescents enrolled in a weight-management program with their peers who do not receive any intervention. However, our study has some limitations. For example, comparison between two different groups and short period of the intervention Longitudinal studies are needed to determine the effect of weight management program on BMI and PA.

\section{Conclusion}

The findings will help to give evidence-based information for health care providers regarding to obesity management and prevention in adolescents. This study found that obese adolescents reported significantly more minutes of physical activity per week when they enrolled in weight management program that includes diet, PA, and behavioral modification. The findings also suggest that the weight-management program may reduce the time of sedentary behaviors of obese Saudi adolescents. Our study demonstrated that weight management program was feasible for obese adolescents. Furthermore, the difference in BMI-SDS reduction between the new patients and weight managed patients is considered significant. Studies are needed to assess long-term weight loss efficacy and clinical significance.

\section{Acknowledgements}

The study was conducted in cooperation with the obesity clinic team in King Khaled University hospital and was funded by King Abdul-Aziz City for Science and Technology.

\section{References}

[1] World Health Organization (2000) Obesity: Preventing and Managing the Global Epidemic. No. 894. World Health Organization.

[2] Daniels, R.S. (2006) From Critical Periods for Abnormal Weight Gain in Children and Adolescents. In: Goran, S.M.I. and Sothern, M.S., Ed., Handbook of Pediatric Obesity: Etiology, Pathophysiology \& Prevention, Taylor \& Francis Group, Florida, 67-75.

[3] El Mouzan, M.I., Foster, P.J., Al Herbish, A.S., et al. (2010) Prevalence of Overweight and Obesity in Saudi Children and Adolescents. Annals of Saudi Medicine, 30, 203-208. http://dx.doi.org/10.4103/0256-4947.62833

[4] Al-Hazzaa, H.M., et al. (2011) Physical Activity, Sedentary Behaviors and Dietary Habits among Saudi Adolescents Relative to Age, Gender and Region. International Journal of Behavioral Nutrition and Physical Activity, 8, 140. http://dx.doi.org/10.1186/1479-5868-8-140

[5] McManus, A.M. and Mellecker, R.R. (2012) Physical Activity and Obese Children. Journal of Sport and Health Science, 1, 141-148. http://dx.doi.org/10.1016/j.jshs.2012.09.004

[6] Department of Health; Physical Activity; Health Improvement and Protection (2011) Start Active, Stay Active: A Report on Physical Activity from the Four Home Countries' Chief Medical Officers. Department of Health, London.

[7] Physical Activity Guidelines Advisory Committee (2008) Physical Activity Guidelines Advisory Committee Report. U.S. Department of Health and Human Services, Washington DC.

[8] Sedentary Behaviour and Obesity Expert Working Group (2010) Sedentary Behaviour and Obesity: Review of the Current Scientific Evidence. Department of Health, London.

[9] Friedemann, C., et al. (2012) Cardiovascular Disease Risk in Healthy Children and Its Association with Body Mass Index: Systematic Review and Meta-Analysis. BMJ, 345, e4759. http://dx.doi.org/10.1136/bmj.e4759

[10] Knowler, W.C., Barrett-Connor, E., Fowler, S.E., et al. (2002) Diabetes Prevention Program Research Group. Reduction in the Incidence of Type 2 Diabetes with Lifestyle Intervention or Metformin. New England Journal of Medicine, 346, 393-403. http://dx.doi.org/10.1056/NEJMoa012512

[11] Wadden, T.A., Webb, V.L., Moran, C.H. and Bailer, B.A. (2012) Lifestyle Modification for Obesity: New Developments in Diet, Physical Activity, and Behavior Therapy. Circulation, 125, 1157-1170. http://dx.doi.org/10.1161/CIRCULATIONAHA.111.039453

[12] Cliff, D.P., et al. (2010) The Impact of Child and Adolescent Obesity Treatment Interventions on Physical Activity: A Systematic Review. Obesity Reviews, 11, 516-530. http://dx.doi.org/10.1111/j.1467-789X.2009.00625.x

[13] American Academy of Pediatrics (2014) Basic Recommendations for Promoting Physical Activity. 
www.aap.org/family/physicalactivity/physicalactivity.htm

[14] American Heart Association (1996) Dietary Guidelines for American Children: A Statement for Health Professionals from the Nutrition Committee, American Heart Association. Circulation, 94, 1795-1800. http://dx.doi.org/10.1161/01.CIR.94.7.1795

[15] Cole, T.J., Bellizzi, M.C., Flegal, K.M. and Dietz, W.H. (2000) Establishing a Standard Definition for Child Overweight and Obesity Worldwide: International Survey. British Medical Journal, 320, 1240-1243. http://dx.doi.org/10.1136/bmj.320.7244.1240

[16] Al-Hazzaa, H.M. and Al-Ahmadi, M. (2003) A Self-Reported Questionnaire for the Assessment of Physical Activity in Youth 15 - 25 Years: Development, Reliability and Construct Validity. Arabian Journal of Science and Engineering, 4, 279-291.

[17] Al-Hazzaa, H.M., Al-Sobayel, H.I. and Musaiger, A.O. (2011) Convergent Validity of the Arab Teens Lifestyle Study (ATLS) Physical Activity Questionnaire. International Journal of Environmental Research and Public Health, 8, 3810-3820. http://dx.doi.org/10.3390/ijerph8093810

[18] Ridley, K., Ainsworth, B.E. and Olds, T.S. (2008) Development of a Compendium of Energy Expenditures for Youth. International Journal of Behavioral Nutrition and Physical Activity, 5, 45.

[19] Ainsworth, B.E., et al. (2000) Compendium of Physical Activities: An Update of Activity Codes and MET Intensities. Medicine and Science in Sports and Exercise, 32, S498-S504.

[20] Kesäniemi, A., Riddoch, C.J., Reeder, B., Blair, S.N. and Sørensen, T.I.A. (2010) Review Advancing the Future of Physical Activity Guidelines in Canada: An Independent Expert Panel Interpretation of the Evidence. The International Journal of Behavioral Nutrition and Physical Activity, 7, 41. http://dx.doi.org/10.1186/1479-5868-7-41

[21] Hills, A.P., Andersen, L.B. and Byrne, N.M. (2011) Physical Activity and Obesity in Children. British Journal of Sports Medicine, 45, 866-870.

[22] Ho, M., et al. (2012) Effectiveness of Lifestyle Interventions in Child Obesity: Systematic Review with Meta-Analysis. Pediatrics, 130, e1647-e1671.

[23] Hughes, A.R., et al. (2008) Randomized, Controlled Trial of a Best-Practice Individualized Behavioral Program for Treatment of Childhood Overweight: Scottish Childhood Overweight Treatment Trial (SCOTT). Pediatrics, 121, e539e546. http://dx.doi.org/10.1542/peds.2007-1786

[24] McCallum, Z., et al. (2007) Outcome Data from the LEAP (Live, Eat and Play) Trial: A Randomized Controlled Trial of a Primary Care Intervention for Childhood Overweight/Mild Obesity. International Journal of Obesity, 31, 630-636.

[25] Nemet, D., Barkan, S., Epstein, Y., Friedland, O., Kowen, G. and Eliakim, A. (2005) Short-and Long-Term Beneficial Effects of a Combined Dietary-Behavioral-Physical Activity Intervention for the Treatment of Childhood Obesity. Pediatrics, 115, e443-e449. http://dx.doi.org/10.1542/peds.2004-2172

[26] Seo, D.-C. and Sa, J. (2008) A Meta-Analysis of Psycho-Behavioral Obesity Interventions among US Multiethnic and Minority Adults. Preventive Medicine, 47, 573-582. http://dx.doi.org/10.1016/j.ypmed.2007.12.010

[27] Metcalf, B., Henley, W. and Wilkin, T. (2012) Effectiveness of Intervention on Physical Activity of Children: Systematic Review and Meta-Analysis of Controlled Trials with Objectively Measured Outcomes (EarlyBird 54). BMJ, 345, e5888. http://dx.doi.org/10.1136/bmj.e5888

[28] Swinburn, B.A., et al. (2011) The Global Obesity Pandemic: Shaped by Global Drivers and Local Environments. The Lancet, 378, 804-814. http://dx.doi.org/10.1016/S0140-6736(11)60813-1

[29] Wing, R.R. (1999) Physical Activity in the Treatment of the Adulthood Overweight and Obesity: Current Evidence and Research Issues. Medicine and Science in Sports and Exercise, 31, S547-S552. http://dx.doi.org/10.1097/00005768-199911001-00010

[30] Vogels, N., Egger, G., Plasqui, G. and Westerterp, K.R. (2004) Estimating Changes in Daily Physical Activity Levels over Time: Implication for Health Interventions from a Novel Approach. International Journal of Sports Medicine, 25, 607-610. http://dx.doi.org/10.1055/s-2004-820950

[31] Al-Hazzaa, H.M. (2002) Physical Activity, Fitness and Fatness among Saudi Children and Adolescents: Implications for Cardiovascular Health. Saudi Medical Journal, 23, 144-150.

[32] Brennan, L., Walkley, J., Wilks, R., Fraser, S.F. and Greenway, K. (2013) Physiological and Behavioural Outcomes of a Randomised Controlled Trial of a Cognitive Behavioural Lifestyle Intervention for Overweight and Obese Adolescents. Obesity Research \& Clinical Practice, 7, e23-e41. http://dx.doi.org/10.1016/j.orcp.2012.02.010

[33] Bauman, A.E., et al. (2012) Correlates of Physical Activity: Why Are Some People Physically Active and Others Not? The Lancet, 380, 258-271. http://dx.doi.org/10.1016/S0140-6736(12)60735-1

[34] Al-Eisa, E., Buragadda, S. and Melam, G.R. (2014) Association between Physical Activity and Psychological Status among Saudi Female Students. BMC Psychiatry, 14, 238. 
[35] Malinauskas, B.M., Raedeke, T.D., Aeby, V.G., Smith, J.L. and Dallas, M.B. (2006) Dieting Practices, Weight Perceptions, and Body Composition: A Comparison of Normal Weight, Overweight, and Obese College Females. Nutrition Journal, 5, 11. http://dx.doi.org/10.1186/1475-2891-5-11

[36] Dumith, S.C., Hallal, P.C., Reis, R.S. and Kohl III, H.W. (2011) Worldwide Prevalence of Physical Inactivity and Its Association with Human Development Index in 76 Countries. Preventive Medicine, 53, 24-28. http://dx.doi.org/10.1016/j.ypmed.2011.02.017

[37] Al-Eisa, E.S. and Al-Sobayel, H.I. (2012) Physical Activity and Health Beliefs among Saudi Women. Journal of Nutrition and Metabolism, 2012, Article ID: 642187. http://dx.doi.org/10.1155/2012/642187

[38] Machado-Rodrigues, A.M., Coelho e Silva, M.J., Mota, J., Santos, R.M., Cumming, S.P. and Malina, R.M. (2012) Physical Activity and Energy Expenditure in Adolescent Male Sport Participants and Nonparticipants Aged 13 to 16 Years. Journal of Physical Activity and Health, 9, 626-623.

[39] Al-Nakeeb, Y., et al. (2012) Obesity, Physical Activity and Sedentary Behavior amongst British and Saudi Youth: A Cross-Cultural Study. International Journal of Environmental Research and Public Health, 9, 1490-1506. http://dx.doi.org/10.3390/ijerph9041490

[40] Braithwaite, I., et al. (2013) The Worldwide Association between Television Viewing and Obesity in Children and Adolescents: Cross Sectional Study. PLoS ONE, 8, e74263.

[41] Tremblay, M.S., et al. (2011) Systematic Review of Sedentary Behaviour and Health Indicators in School-Aged Children and Youth. International Journal of Behavioral Nutrition and Physical Activity, 8, 98.

[42] Strasburger, V.C. (2011) Children, Adolescents, Obesity, and the Media. Pediatrics, 128, 201-208. http://dx.doi.org/10.1542/peds.2011-1066

[43] Danielsson, P., Kowalski, J., Ekblom, Ö. and Marcus, C. (2012) Response of Severely Obese Children and Adolescents to Behavioral Treatment. Archives of Pediatrics \& Adolescent Medicine, 166, 1103-1108. http://dx.doi.org/10.1001/2013.jamapediatrics.319

[44] Whitlock, E.P., et al. (2010) Effectiveness of Weight Management Interventions in Children: A Targeted Systematic Review for the USPSTF. Pediatrics.

[45] Oude Luttikhuis, H., et al. (2009) Interventions for Treating Obesity in Children. The Cochrane Library.

[46] Ströbl, V., Knisel, W., Landgraf, U. and Faller, H. (2013) A Combined Planning and Telephone Aftercare Intervention for Obese Patients: Effects on Physical Activity and Body Weight after One Year. Journal of Rehabilitation Medicine, 45, 198-205. http://dx.doi.org/10.2340/16501977-1095

[47] Wafa, S.W. (2012) Randomised Controlled Trial of a Good Practice Approach to Treatment of Childhood Obesity and Health-Related Quality of Life and Habitual Physical Activity and Sedentary Behaviour of Obese Children in Malaysia. Dissertation, University of Glasgow, Glasgow.

\section{Submit or recommend next manuscript to SCIRP and we will provide best service for you:}

Accepting pre-submission inquiries through Email, Facebook, LinkedIn, Twitter, etc.

A wide selection of journals (inclusive of 9 subjects, more than 200 journals)

Providing 24-hour high-quality service

User-friendly online submission system

Fair and swift peer-review system

Efficient typesetting and proofreading procedure

Display of the result of downloads and visits, as well as the number of cited articles

Maximum dissemination of your research work

Submit your manuscript at: http://papersubmission.scirp.org/ 